\title{
Paniculitis septal y sindrome de Löfgren en varon de 39 años
}

\author{
López Soberón. E. ${ }^{1}$, Menéndez Martínez MaA. ${ }^{2}$, Fernández Bermejo L. ${ }^{3}$, Jareño Esteban JJ.4 \\ Sanid. mil. 2015; 71 (4): 249-251; ISSN: 1887-8571
}

\section{RESUMEN}

Presentamos el caso de un varón de 39 años con un cuadro de tumefacción dolorosa de color rojo violáceo en el dorso de los miembros inferiores, fiebre y adenopatías hiliares bilaterales. Se realizó biopsia de las lesiones cutáneas y de las adenopatías mediastínicas, obteniéndose el diagnóstico de eritema nodoso y sarcoidosis respectivamente. La asociación de estos hallazgos clínicos y anatomopatológicos hicieron posible el diagnóstico de Síndrome de Löfgren.

PALABRAS CLAVE: Paniculitis septal, Eritema nudoso, Sarcoidosis, Síndrome de Löfgren.

\section{Septal Panniculitis and Löfgren's syndrome in a 39 year- old male}

SUMMARY: Case report is about a 39 year- old male with a clinical profile of painful swelling purplish red at the back of lower limbs, fever and bilateral, hilar lymphadenopathy. Biopsy of skin lesions and mediastinal lymph nodes was performed, resulting in the diagnosis of sarcoidosis and erythema nodosum respectively. The association of these clinical and pathological findings made possible the diagnosis of Löfgren syndrome.

KEYWORDS: Septal Panniculitis, erythema nodosum, Sarcoidosis, Löfgren's syndrome.

\section{INTRODUCCIÓN}

La sarcoidosis es una enfermedad inflamatoria multisistémica de etiología desconocida que se caracteriza por la aparición de granulomas no caseificantes. Los órganos que se afectan con mayor frecuencia son el pulmón (más del $90 \%$ de los casos), la piel y los ojos. Entre las lesiones dermatológicas clásicas se incluyen las maculopapulosas, hiperpigmentación e hipopigmentación, nódulos subcutáneos, formación de queloides, lupus pernio y el eritema nudoso, una manifestación no específica de la enfermedad pero que asociado a otros hallazgos puede orientar hacía su diagnóstico. El curso clínico es progresivo, aunque se suelen alternar recaídas con periodos de remisión. El síndrome de Löfgren es una forma de sarcoidosis caracterizada por la asociación de eritema nodoso (EN), adenopatías hiliares bilaterales y artritis o $\operatorname{artralgias^{1,2}}$. $^{2}$

\section{CASO CLÍNICO}

Un varón de 39 años, no fumador, originario de Perú, residente en España en los últimos 8 años, sin antecedentes médicos de interés presentaba 2 semanas antes de su ingreso en nuestro Servicio un cuadro de tumefacción dolorosa de color violáceo en el dorso del

\footnotetext{
${ }^{1}$ Cap. Médico. Servicio de Cardiología.

${ }^{2}$ FEA. Servicio de Medicina interna.

${ }^{3}$ MIR. Servicio de Medicina interna.

${ }^{4}$ FEA. Servicio de Neumología.

Hospital Central de la Defensa "Gómez Ulla". Madrid. España.
}

Dirección para correspondencia: Dra. Edurne López Soberón. Servicio De Cardiología. Hospital Central de la Defensa "Gómez Ulla". Glorieta del Ejército 1. Madrid 28047. elopsob@fn.mde.es

Recibido: 3 de marzo de 2015

Aceptado: 8 de agosto de 2015 miembro inferior izquierdo que progresó a la cara anterior de la pierna tras un traumatismo mínimo en la zona. La lesión no mejoró a pesar de tratamiento antibiótico y antiinflamatorio. Una semana después comenzó con los mismos síntomas en el miembro inferior derecho, añadiéndose fiebre termometrada de hasta $39^{\circ} \mathrm{C}$. En la exploración el paciente se encontraba afebril, no se palpaban adenopatías, la auscultación pulmonar y cardíaca eran normales, en el abdomen no se apreciaban datos de interés. En la exploración de las extremidades inferiores destacaba un eritema y edema de borde no definido en cara anterior y lateral de ambos miembros hasta las rodillas, más evidente en el izquierdo, doloroso a la presión y sin inflamación articular.

En la analítica se observaba una leucocitosis de $21.000 / \mathrm{ml}$ con neutrofilia y linfopenia, velocidad de sedimentación: $67 \mathrm{~mm} / \mathrm{h}$, proteína C reactiva: $24,48 \mathrm{mg} / \mathrm{dl}$ y aumento de los reactantes de fase aguda. La radiografía postero-anterior de tórax revelaba una lesión nodular de 2,2 cm de diámetro en hilio izquierdo, sugestiva de adenopatía hiliar. Los hemocultivos y urocultivos fueron negativos, la serología a virus de Hepatitis A, B y C, borrelia, rickettsia conorii, coxiella, virus de Epstein Barr, y citomegalovirus no aportaba datos concordantes con infección aguda. Los BAAR y cultivos de esputo en medios habituales y el Mantoux fueron negativos. Se realizó un TC toraco-abdomino-pélvico en el que se pusieron de manifiesto adenopatías mediastínicas de tamaño significativo a nivel paratraqueal derecho, pretraqueal y perivascular e hiliar bilateral de naturaleza indeterminada. Adyacente a la cúpula diafragmática y a nivel de los segmentos basales del LII, se observó una imagen pseudonodular de unos 2,2 cm de diámetro anteroposterior, de aspecto inflamatorio, sin poderse descartar otras posibilidades. Ambas cisuras mayores presentaban aspecto engrosado con pequeña cuña de líquido en el lado derecho.

Se realizó una fibroboncoscopia con toma de broncoaspirado (BAS), lavado broncoalveolar (LBA), biopsia bronquial y transbronquial. El LBA revelo una celularidad de predominio linfocitario 


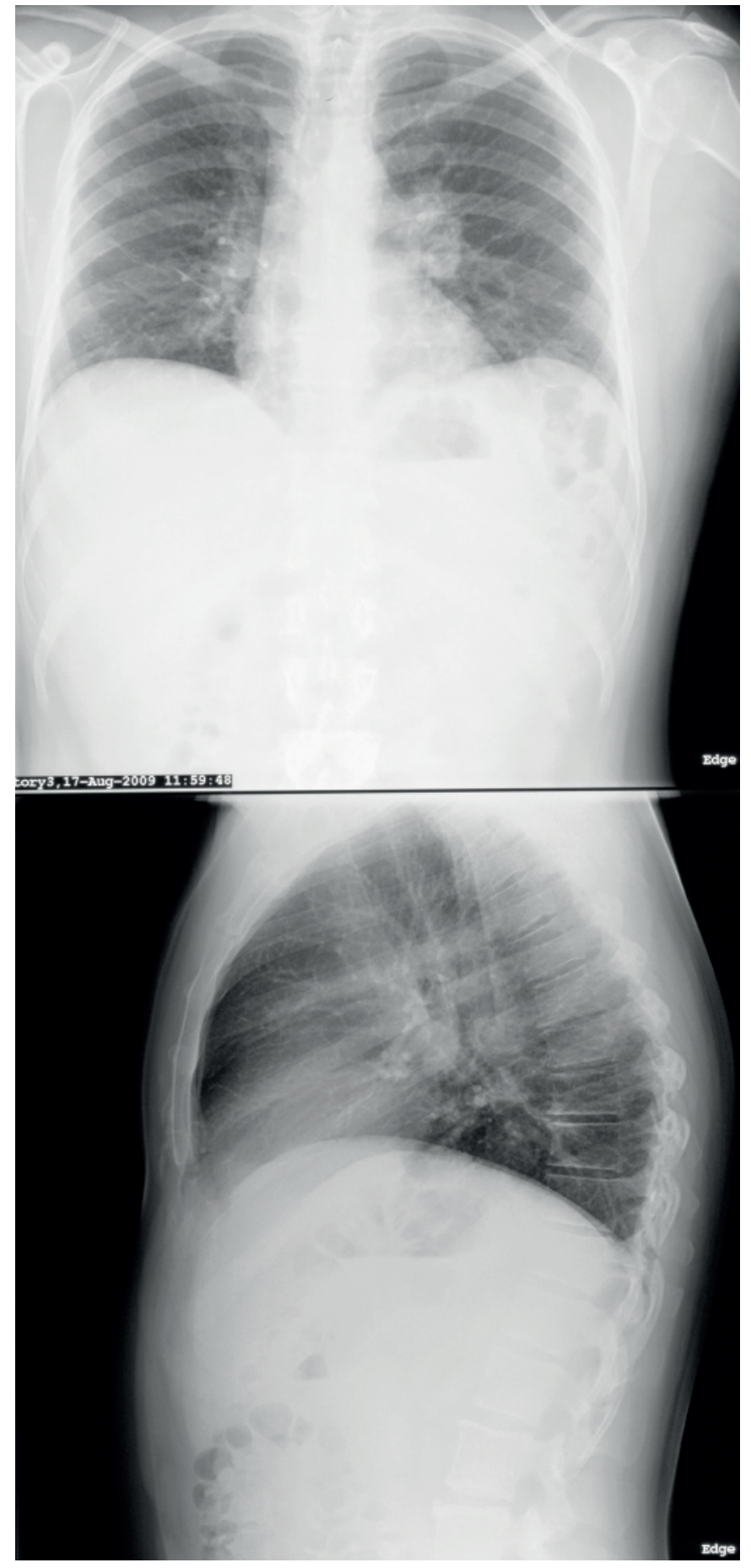

Figura 1. Radiografía posteroanterior de tórax y lateral con lesión nodular de 2,2 cm de diámetro en hilio izquierdo, sugestiva de adenopatía hiliar.

con un cociente CD4/CD8 > 3,5 y la biopsia bronquial y transbronquial reveló un epitelio respiratorio maduro, con glándulas mucosas y acúmulos linfoides aislados en la lámina propia. No se encontraron elementos granulomatosos ni sugerentes de malignidad. Se realizó una mediastinoscopia con biopsia de una adenopatía paratraqueal derecha que mostró un glanglio linfático ocupado en su mayor parte por granulomas de tipo sarcoideo, pequeños y coalescentes, con densa corona linfocitaria y sin necrosis central, no objetivándose estructuras bacilares, compatible con linfadenitis granulomatosa,

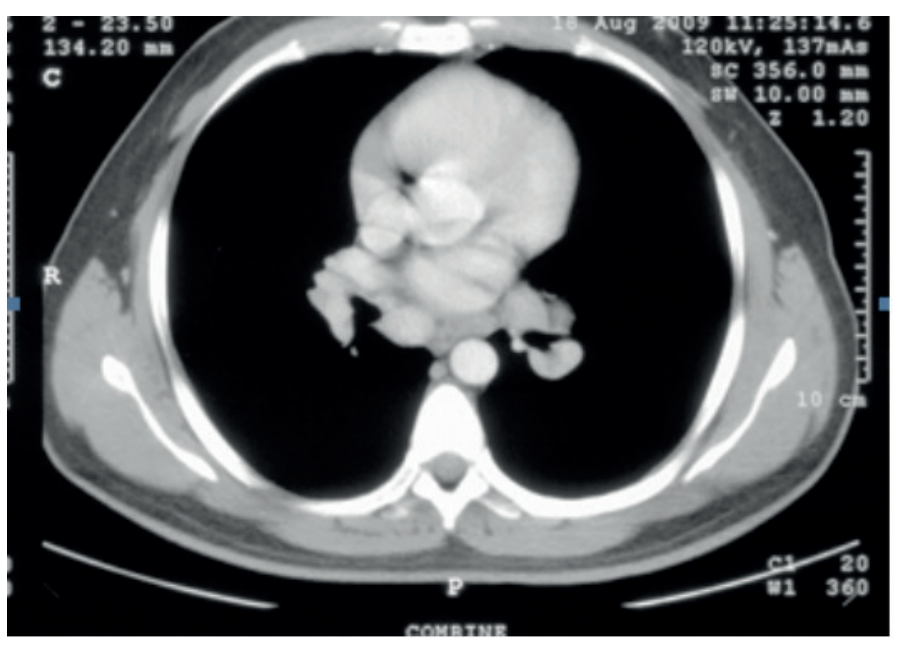

Figura 2. TAC torácico con presencia de adenopatías mediastínicas hiliares bilaterales.

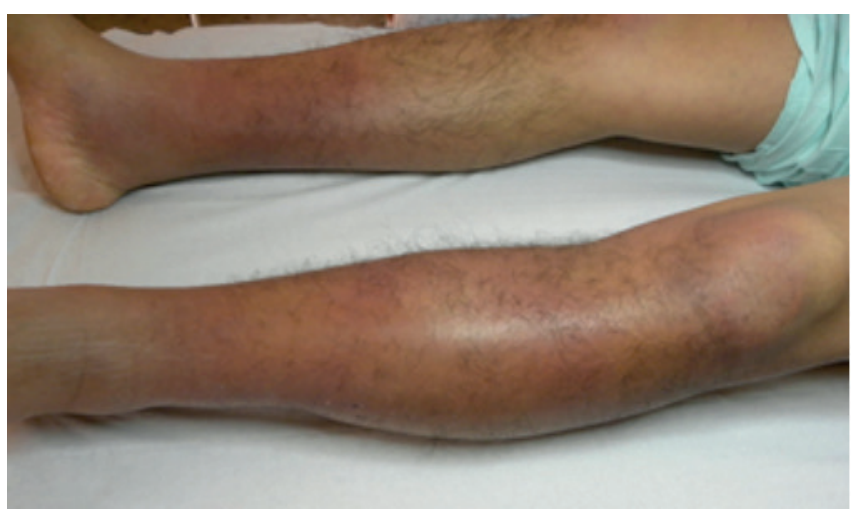

Figura 3. Lesiones cutáneas compatibles con eritema nodoso.

sarcoidosis. Se tomó una muestra de piel, cuya histología mostró un nódulo inflamatorio en tejido celular subcutáneo constituido por histiocitos, algunos con aspecto epitelioide, polimorfonucleares, neutrófilos y linfocitos aislados, compatible con eritema nodoso. La espirometría y la difusión pulmonar fueron normales así como el fondo de ojo.

Ante los hallazgos clínicos y la biopsia compatible con granuloma sarcoideo se instauró tratamiento con corticoides.

\section{DISCUSIÓN}

La sacoidosis es una enfermedad granulomatosa de etiología desconocida. Su incidencia varía en función de edad, sexo, raza y zona geográfica, estimándose en 16,5/100.000 en hombres y $19 / 100.000$ en mujeres. Es más frecuente por tanto en mujeres y en la raza negra que en población caucasiana ${ }^{1,2}$.

En 1953 Löfgren estudió una serie de 212 pacientes adultos, diagnosticados de sarcoidosis, que presentaban adenopatías hiliares bilaterales, eritema nudoso al comienzo de la enfermedad, y afectación articular con dolor e inflamación, considerándola una forma de presentación aguda benigna de sarcoidosis, que denominó Síndrome de Löfgren ${ }^{2,3}$. 
En nuestro país han sido publicados varios estudios retrospectivos que revelan un predominio en mujeres (64\%), con edad media de 42 años y en el $60 \%$ de los casos se manifiesta con la triada clásica de la enfermedad ${ }^{4,5}$. En los varones es más frecuente la afectación articular que el eritema nodoso, lo que reflejaría polimorfismos de la enfermedad ${ }^{6,7}$. En pocas ocasiones se requiere una confirmación histológica para su diagnóstico. En nuestro caso presentamos un varón natural de Perú, con manifestaciones clínicas de Síndrome de Löfgren, lo que no es habitual en nuestro medio. Esto nos obligó a la realización de técnicas de diagnóstico, incluyendo broncoscopia, mediastinoscopia y biopsia cutánea, que confirmó el diagnóstico.

El Síndrome de Löfgren presenta diferencias analíticas respecto a las formas crónicas de sarcoidosis. Así, la enzima conversora de angiotensina A (ECA), ampliamente utilizada en en el diagnóstico, está disminuida o normal en este síndrome e incrementada en las sarcoidosis de larga evolución ${ }^{1,8}$. También en algunos estudios se ha observado elevación de la proteína $\mathrm{C}$ reactiva (PCR), llevando a la especulación sobre un posible efecto protector de la PCR en las formas benignas de sarcoidosis como el síndrome de Löfgren ${ }^{2}$. Recientemente en el síndrome de Löfgren se ha descrito la asociación con el ántígeno HLA-DQB1*0201 y polimorfismos específicos del receptor de la cimoquina 2 (CCR2) ligados a un buen pronóstico ${ }^{8}$.

En general dos tercios de los pacientes con sarcoidosis presentan regresión de la enfermedad en el curso de uno a tres años de forma espontánea o con tratamiento.

El eritema nodoso es una manifestación con buena respuesta al tratamiento con corticoides como ocurrió en el caso que presentamos, pero los antiinflamatorios no esteroideos (indometacina, colchicina, etc.) han sido también utilizados con éxito ${ }^{9,10}$.
Finalmente podemos concluir que el síndrome de Löfgren es una variante benigna de sarcoidosis con un patrón clínico característico que en pocas ocasiones requiere confirmación histológica y tiene un buen pronóstico.

\section{BIBLIOGRAFÍA}

1. Iannuzzi MC, Rybicki BA, Terestein AS. Sarcoidosis. N Engl J Med 2007; 357: 2153-65.

2. Paucar K, Del Solar M, Bravo F, Salomón M, Puell L, Feria K, Ramos C, Giglio P. Sarcoidosis: Síndrome de Löfgren.Folia Dermatológica Perú. 2011; 22(2): 107113.

3. Grunewald J,Eklund A. Sex-specific manifestations of Löfgren's. Am J Respir Crit Care Med. 2007;175:40-4

4. Maña J, Gomez-Vaquero C, Montero A, Salazar A, Marcoval J, Valverde J et al. Löfgren's syndrome revisited: A study of 186 patients. Am J Med. 1999;107:2405

5. Tejera B, Holgado S, Mateo L, Pego-Reigosa JM, Carnicero M, Olivé A. Síndrome de Löfgren: estudio de 80 casos. Med Clin 2014; 143:163-5.

6. Otsa H, Tazawa R, Nakamura A, Kimura Y, Maemondo M, Kikuchi T et al. Acute-onset Sarcoidosis with Erytema Nodosum and Poliarthralgia (Löfgren's Syndrome) in Japan: a Case Report and a Review of the literature. Intern Med 2006; 45(9):659-62.

7. Krasowska D, Schwartz RA, Wojnowska D, Maćkiewicz B, Czelej D. Polymorphous cutaneous and chronic multisystem sarcoidosis. Acta Dermatovenerol Alp Panonica Adriat. 2008 Mar; 17(1):26-30

8. Rudralingam M, Nolan A, Macleod I, Greenwood M, Heath N. A case of sarcoidosis presenting with diffuse bilateral swelling of the salivary glands. Dent Update. 2007; 34:439-42.

9. Paramothayan S, Jones PW. Corticosteroid theraphy in pulmonary sarcoidosis: a systematic rewiew. JAMA. 2002; 287: 1301-7.

10. Grunters JC, Van den Bosch JMM. Corticosteroid treatment in sarcoidosis. Eur Respir J. 2006; 28:627-36. 